\title{
Adverse Maternal Outcomes in High-Order Multiple Pregnancies in a Private Health Facility in Nigeria: A 10-Year Experience
}

\author{
Vaduneme Kingsley Oriji1,2*, Solomon N. Nyeche1,2 \\ ${ }^{1}$ Department of Obstetrics and Gynaecology, University of Port Harcourt Teaching Hospital, Port Harcourt, Nigeria \\ ${ }^{2}$ Prime Medical Consultant Hospital No. 1 Prime Close, Eliada Estate, Port Harcourt, Nigeria \\ Email: *vadoriji@gmail.com
}

How to cite this paper: Oriji, V.K. and Nyeche, S.N. (2020) Adverse Maternal Outcomes in High-Order Multiple Pregnancies in a Private Health Facility in Nigeria: A 10-Year Experience. Journal of Biosciences and Medicines, 8, 103-110.

https://doi.org/10.4236/jbm.2020.84009

Received: March 11, 2020

Accepted: April 12, 2020

Published: April 15, 2020

Copyright $\odot 2020$ by author(s) and Scientific Research Publishing Inc. This work is licensed under the Creative Commons Attribution International License (CC BY 4.0).

http://creativecommons.org/licenses/by/4.0/

\begin{abstract}
Background: Naturally occurring high-order multiple (HOM) pregnancies are rare $(1-7$ per 10,000) even in Nigeria noted to have the highest twinning rates. Worldwide multiple pregnancies are increasing and are associated with increased adverse maternal outcomes. Materials and Methods: This was a retrospective study of all patients with HOM pregnancy in Prime Medical Consultants between Jan 2004 to Dec 2013. We identified all the patients with high-order multiple pregnancy and extracted relevant data from the ante-natal and labour ward records, theatre records, and patients case notes. Demographic characteristics, gestational age at delivery, preterm rupture of membranes, preterm labour, hypertensive disease in pregnancy, proteinuria, anaemia, and postpartum haemorrhage were data extracted from the records. Results: The incidence of HOM pregnancy in this hospital was $0.24 \%$. The mean maternal age was $35.7 \pm 1.81$ years. Over $85 \%$ of all the high-order multiple pregnancies in this hospital were from in-vitro fertilization and embryo transfer treatments for infertility. About $11 \%$ of the HOM pregnancy ended as spontaneous miscarriages. The mean gestational age at birth was $31 \pm 1.5$ weeks, and primary postpartum haemorrhage (22.2\%) was the most common maternal adverse outcome from birth. Conclusion: The high incidence of HOM pregnancy in this hospital was mainly from in-vitro fertilization and embryo transfer. The HOM pregnancies are associated with high occurrence of preterm labour, caesarean sections and primary postpartum haemorrhage.
\end{abstract}

\section{Keywords}

High-Order Multiple Pregnancy, IVF-ET, Preterm Labour, Primary Postpartum Haemorrhage 


\section{Introduction}

Natural high-order multiple pregnancies (i.e. pregnancies with more than two foetuses in-utero) are uncommon. The reported incidence ranges from $1-7$ per 10,000 of all pregnancies. Worldwide, Nigeria is recognized to have the highest incidence of multiple births, including high-order births [1] [2] [3] [4] [5]. In Nigeria, about $35 \%$ of institutional deliveries occur in private medical institutions [6] and there has been an increase in the incidence of multiple births and HOM pregnancy in current day obstetric practice. The increase in the incidence of high-order multiple pregnancies is estimated to be over ten folds that of previous occurrences and has been attributed to several factors. The factors include the use of ovulation-inducing agents and assisted reproductive technologies to treat infertility as well as a shift towards late childbearing in women when multiple gestations are naturally more likely to occur [3] [4] [5]. Infertility may induce the desire to have multiple pregnancies in women having such challenges. In Nigeria, the desire for multiple pregnancies, in infertile women, has been documented [7] and fertility practitioners readily transfer over two embryos during in vitro-fertilization and embryo transfer (IVF-ET) treatment cycles with attendant increase in multiple pregnancies [8] [9].

Multiple pregnancies including HOM pregnancies are associated with adverse pregnancy outcomes in the mother such as increase in spontaneous miscarriages, preterm term labour, preterm drainage of liquor, hypertensive diseases in pregnancy, caesarean section, antepartum and postpartum haemorrhage. These invariably increase hospital admissions causing dislocations in family, social and economic life of the woman and her family [10]. Several interventions such as prophylactic cervical cerclage, prolonged hospital admissions with bed rest or the use of progestogens, have been instituted to improve the pregnancy outcome of multiple pregnancies with no clear evidence of the efficacy of these interventions, which may sometimes be harmful [11] [12]. The best intervention, therefore, lies with preventing the HOM pregnancies.

The proliferation of fertility clinics within our environment, the high incidence of HOM pregnancies following fertility treatments, as well as the associated high maternal morbidity and sometimes mortality from the HOM pregnancies is the reason for initiating this study which aims to evaluate adverse pregnancy outcomes in women with $\mathrm{HOM}$ pregnancies at a specialist private health care facility.

\section{Materials and Methods}

This study was a descriptive retrospective study of all the higher-order multiple births managed and delivered in Prime Medical Consultants between January 2004 and December 2013.

Prime Medical Consultants is a private health care facility situated in Port Harcourt city, Rivers State, Nigeria, with 24-hours-coverage by consultant obstetricians and neonatologists. It has fully functional obstetric and special care 
baby units. We retrieved information from antenatal clinic records, labour ward records, theatre records, and case files of women with high-order multiple pregnancies, for various maternal data. The data collected were age, parity, educational status, gestational age at delivery, hospital admissions, use of prophylactic cerclage, preterm labour (defined as uterine contractions that caused progressive cervical dilatations before at 37 weeks gestation), premature rupture of fetal membranes (drainage of amniotic fluid before 37 weeks gestation). Others are gestational hypertension (defined as an elevation of blood pressure greater than or equal to $140 / 90 \mathrm{mmHg}$ on two consecutive readings, 4 hours apart, occurring with or without proteinuria), anaemia (defined as haemoglobin concentration of $<10.0 \mathrm{~g} / \mathrm{dl}$ ) and antepartum haemorrhage, primary postpartum haemorrhage (defined as blood loss above $500 \mathrm{mls}$ following vaginal delivery; or above 1000 mls following caesarean delivery). Data analysis was carried out using SPSS version-15 software and the results presented as frequencies, percentages, mean and standard deviation.

\section{Results}

There were a total of 7634 deliveries during the study period. Eighteen of the deliveries were high-order multiple pregnancy, comprising 14 triplets and four quadruplet pregnancies. The overall incidence of high-order pregnancy was $0.24 \%$ of all deliveries in this hospital. A set of triplets and another set of quadruplets were through natural conception and ovulation induction with clomiphene citrate respectively. The other 16 sets (89\%) of HOM pregnancy were through fertility treatment with in-vitro fertilization and embryo transfer. The mean maternal age was $35.1 \pm 4.81$ years. Majority of the women $(66.7 \%)$ were nulliparous with tertiary education (78\%). See Table 1 . The mean gestational age at delivery was $31 \pm$ 1.5 weeks, as $83.3 \%$ of the deliveries were preterm. See Table 2 .

Table 1. Demographic characteristics of mothers.

\begin{tabular}{ccc}
\hline AGE (YRS) & Freq. & $\%$ \\
\hline $20-24$ & 1 & 5.6 \\
$25-29$ & 3 & 16.7 \\
$30-34$ & 2 & 11.1 \\
$35-39$ & 8 & 44.4 \\
$40-44$ & 4 & 22.2 \\
$\geq 45$ & Nil & NIL \\
TOTAL & 18 & 100 \\
PARITY & Freq. & $\%$ \\
0 & 12 & 66.7 \\
$1-4$ & 5 & 27.8 \\
$\geq 5$ & 1 & 5.6 \\
\hline
\end{tabular}


Continued

\begin{tabular}{ccc}
\hline TOTAL & $\mathbf{1 8}$ & $\mathbf{1 0 0}$ \\
EDUCATIONAL STATUS & Freq. & $\%$ \\
NONE & NIL & 0 \\
PRIMARY & NIL & 0 \\
SECONDARY & 4 & 22.2 \\
TERTIARY & 14 & 77.8 \\
TOTAL & $\mathbf{1 8}$ & $\mathbf{1 0 0 \%}$ \\
\hline
\end{tabular}

Table 2. Adverse outcomes during antenatal care.

\begin{tabular}{ccc}
\hline ANTENATAL EVENTS & Freq. & $\%$ \\
\hline Spontaneous miscarriage & 2 & 11.1 \\
Cervical cerclage in pregnancy & 14 & 77.8 \\
Preterm rupture of membranes & 7 & 38.8 \\
Preterm deliveries & 14 & 87.5 \\
Anaemia in pregnancy & 2 & 11.1 \\
Pre-eclampsia in pregnancy & 1 & 5.6 \\
Antepartum Haemorrhage & nil & 0.0 \\
Congestive cardiac failure & 1 & 5.6 \\
Hospital admissions in pregnancy $(7-21$ days) & 11 & 61.1 \\
Hospital admissions in pregnancy $(>21$ days) & 2 & 11.1 \\
\hline
\end{tabular}

All the prophylactic cerclage were inserted between 12 and 14 weeks. One cerclage was inserted in a referral hospital, and three patients registered late for antenatal care and two of them did not have any cerclage. Sixteen of these women had micro-ionized vaginal progesterone treatment for early pregnancy support. Five of them continued progesterone treatment to 12 weeks while others discontinued at confirmation of pregnancy. Two patients had spontaneous first trimester miscarriages, and there was no recorded case of antepartum haemorrhage in these women (Table 3).

Table 3. Indications and methods of delivery.

\begin{tabular}{ccc}
\hline Indications for delivery & Type of delivery & Freq. (\%) \\
\hline Severe pre-eclampsia & Emergency caesarean section & $1(5.6)$ \\
Preterm labour & Emergency caesarean section & $10(62.5)$ \\
Preterm rupture of membrane & Elective caesarean section & $2(11.2)$ \\
Term pregnancy & Elective caesarean section & $1(5.6)$ \\
Late presentation in preterm labour & Spontaneous vaginal delivery & $2(11.2)$ \\
\hline
\end{tabular}

Two women referred to the clinic after 20 weeks had anaemia in pregnancy and postpartum anaemia. They also received blood transfusion in the postpartum period. There were frequent intermittent hospital admissions amongst these 
women. Cumulative admission periods for eleven mothers were between 7 to 14 days while in 2 mothers, cumulative admissions were over 21 days (Table 3 ).

Table 3 and Table 4 show that $77.8 \%$ of the pregnancies were delivered by caesarean sections and $68.75 \%$ by emergency caesarean section. Preterm labour (62.5\%) was the most frequent indication for delivery.

Table 4. Intrapartum and puerperal complications.

\begin{tabular}{ccc}
\hline COMPLICATIONS & Freq. & $\%$ \\
\hline Caesarean sections & 14 & 77.8 \\
Primary postpartum haemorrhage (PPH) & 4 & 22.2 \\
Postpartum anaemia & 2 & 11.1 \\
Postoperative wound infection & 1 & 5.6 \\
Blood transfusion & 4 & 22.2 \\
\hline
\end{tabular}

Primary postpartum haemorrhage ( $\mathrm{PPH}$ ) occurred in $22.2 \%$ of these women and was the leading maternal adverse outcome in the postpartum period.

\section{Discussion}

The incidence of high-order multiple pregnancies in this hospital over the period under study was $0.24 \%$. This incidence represents an increase of 4 to 24 times over the natural rates of high-order multiple pregnancies of $0.01 \%$ to $0.07 \%$ in the literature [1] [2] [3] [4] [5]. This incidence of $0.24 \%$ is higher than $0.1 \%$ to $0.13 \%$ recently reported in the eastern part of Nigeria but lower than $0.72 \%$ published in the western part of Nigeria [3] [4] [5]. The increase in the incidence of high-order multiple pregnancies in this study is mainly from infertility treatments using IVF-ET. Fertility treatment with IVF-ET contributed $88.9 \%$ of these high-order pregnancies, which is similar to other reports in many recent studies from Nigeria [3] [4] [5] [8] [9]. In this study, about $87 \%$ of women with the high-order multiple pregnancies had preterm deliveries. The mean gestational age at delivery was $31 \pm 1.5$ weeks. The gestational age at delivery is similar to other reports around the globe and consistent with a report from America Society of Reproductive Medicine (ASRAM) showing that the risk of birth before 32 weeks of gestation for singleton, twin, triplet, and quadruplet pregnancies was $2,8,26$, and $>95$ per cent, respectively [13]. The presence of prophylactic cerclage in over $75 \%$ of the patients and frequent hospital admissions for bed rest did not seem to prolong the gestational age in these patients. These interventions could not prolong HOM pregnancies in other studies as well [11] [12]. Premature rupture of fetal membranes (38.8\%) and Preterm labour (62\%) with consequent early deliveries were significant problems in these women. The excessive and rapid distension of the uterus in multifetal pregnancies could trigger preterm labour which could account for the high proportion of preterm births $(87 \%)$ in these pregnancies. 
The incidence of caesarean section (87\%) amongst mothers with high-order multiple pregnancy was very high. The primary reason for these caesarean sections was infant survival. Caesarean section has higher morbidity than vaginal deliveries and did contribute to the adverse outcomes observed in these mothers. The high occurrence of other maternal adverse outcomes also noted in these mothers includes primary postpartum haemorrhage (22.2\%). Primary postpartum haemorrhage from uterine atony was the most frequent maternal complication in these women following delivery. The high occurrence of primary PPH has also been reported in other studies as well [5] [6]. Severe pre-eclampsia was uncommon because majority of the pregnancies ended around 30 weeks when pre-eclampsia begins to manifest in pregnant women. No antepartum haemorrhage was reported in these women. Traditionally, the incidence of antepartum haemorrhage is thought to increase in women with multiple pregnancies; however, the absence of antepartum haemorrhage may be due to the small study population.

Mothers with high-order pregnancies also had high cumulative admission periods in the hospital (see Table 3). Their frequent admissions, no doubt, would have caused unanticipated dislocations in family's financial and socioeconomic life as has been reported in a previous study [10].

The practice of multiple embryo transfers ( $>2$ embryos) amongst invitro-fertilization practitioners in Nigeria is accountable for the high occurrence of high-order multiple pregnancies [8] [9]. It is reported that Nigerian mothers welcome and anticipates multifetal pregnancies from invitro-fertilization treatments [7]. However, in wishing multiple pregnancies, these women may not have experienced the adverse medical, financial and socioeconomic effects associated with high-order multiple pregnancies. Recent studies show that transfer of numerous embryos in an IVF treatment cycle does not significantly increase pregnancy rates or take home babies, as initially thought, but substantially increases the occurrence of high-order multiple pregnancy and the adverse effects thereof [14] [15] [16]. To reduce multifetal pregnancies, women undergoing in-vitro fertilization treatment in Nigeria should undergo counselling aimed at reducing the number of embryos transferred to less than three. This reduction is also possible by enacting regulatory laws protecting against the transfer of over two embryos per cycle in a patient. Reducing the number of embryos transferred in a treatment cycle would check the high incidence of high-order multiple pregnancies and the associated adverse outcomes. The overall effect of high-order multiple pregnancy is that it increases morbidity and even mortality to the mothers. Most practitioners agree to elective single embryo transfer as the first step towards reducing the incidence of high-order multiple pregnancies and fetal reduction if the first step of elective single embryo transfer fails. Fetal reduction is an option to bring triplets and quadruplets to twin gestation to reduce the morbidity and mortality generally associated with multifetal pregnancies [17] [18]. 


\section{Conclusion}

This study shows that high-order multiple pregnancies have become commoner and are associated with high preterm births and maternal adverse pregnancy outcomes such as high caesarean section rate and primary postpartum haemorrhage. Effort to reduce the incidence of high-order multiple births should start with electively decreasing the number of embryos transferred at each IVF treatment cycle to less than three.

\section{Conflicts of Interest}

The authors declare no conflicts of interest regarding the publication of this paper.

\section{References}

[1] Nylander, P. (1981) The Factors That Influence Twinning Rates. Acta Geneticae Medicae et Gemellologiae, 30, 189-202. https://doi.org/10.1017/S0001566000007650

[2] Harrison, K.A. (1985) Childbearing Health and Social Priorities: A Survey of 22,774 Consecutive Hospital Births in Zaria, Northern Nigeria. BJOG: An International Journal of Obstetrics \& Gynaecology, 92, 1-119.

[3] Umeora, O.U., Anezi-Okoro, E.A. and Egwuatu, V.E. (2011) Higher-Order Multiple Births in Abakaliki, Southeast Nigeria. Singapore Medical Journal, 52, 163-167.

[4] Ezenwa, B., Oseni, O., Akintan, P., Aligwekwe, P., Chukwukelu, B., Fashola, O., et al. (2017) Higher Order Multiple Births in Nigeria: Experiences, Challenges and Neonatal Outcomes in a Private Health Facility. Nigerian Journal of Clinical Practice, 20, 1439-1443. https://doi.org/10.4103/njcp.njcp_71_17

[5] Chidi, E.O., Sylvester, E.O., Ekop, E., Uka, O.K., Odidika, U.U. and Dierdre, T.E. (2016) Triplet Pregnancies in a Southeastern Nigerian Hospital: Before the Artefacts Set in. Tropical Journal of Obstetrics and Gynaecology, 33, 159-164. https://doi.org/10.4103/0189-5117.192217

[6] National Population Commission (NPC) [Nigeria] and ICF (2019) Nigeria Demographic and Health Survey 2018. NPC and ICF, Abuja, Nigeria, and Rockville, MD.

[7] Okohue, J.E., Onuh, S.O., Ikimalo., J.I. and Wada, I. (2010) Patients' Preference for Number of Embryos Transferred During IVF/ICSI a Nigerian Experience. Nigerian Journal of Clinical Practice, 13, 294-297.

[8] Orhue, A.A., Aziken, M.E., Osemwenkha, A.P., Ibadin, K.O. and Odoma, G. (2012) In Vitro Fertilizationat a Public Hospital in Nigeria. International Journal of Gynecology \& Obstetrics, 8, 56-60. https://doi.org/10.1016/j.ijgo.2012.01.022

[9] Olukoya, O.Y., Okeke, C.C., Ailoje-Ibru, K., Ogbeche, R.O., Adewusi, A.J. and Ashiru, O.A. (2012) Multiple Gestations/Pregnancies from IVF Process in a Fertility Center in Nigeria, 2009-2011: Implementing Policy towards Fewer (Double and Single) Embryo Transfer. Nigerian Quarterly Journal of Hospital Medicine, 22, 80-84.

[10] Strauss, A., Winkler, D., Middendorf, K., Kümper, C., Herber-Jonat, S., Schulze, A., et al. (2008) Higher Order Multiples-Socioeconomic Impact on Family Life. European Journal of Medical Research, 13, 147-153.

[11] Stock, S. and Norman, J. (2010) Preterm and Term Labour in Multiple Pregnancies. In: Seminars in Fetal and Neonatal Medicine, Volume 15, WB Saunders, Philadel- 
phia, PA, 336-341. https://doi.org/10.1016/j.siny.2010.06.006

[12] Strauss, A., Heer, I.M., Janßen, U., Dannecker, C., Hillemanns, P. and Müller-Egloff, S. (2002) Routine Cervical Cerclage in Higher Order Multiple Gestation-Does It Prolong the Pregnancy? Twin Research and Human Genetics, 5, 67-70.

https://doi.org/10.1375/1369052022910

[13] Practice Committee of American Society for Reproductive Medicine (2012) Multiple Gestation Associated with Infertility Therapy: An American Society for Reproductive Medicine Practice Committee Opinion. Fertility and Sterility, 97, 825. https://doi.org/10.1016/j.fertnstert.2011.11.048

[14] Thurin, A., Hausken, J., Hillensjö, T., Jablonowska, B., Pinborg, A. and Strandell, A. (2004) Elective Single-Embryo Transfer versus Double-Embryo Transfer in in Vitro Fertilization. New England Journal of Medicine, 2, 393-402.

https://doi.org/10.1056/NEJMoa041032

[15] Martikainen, H., Tiitinen, A., Tomás, C., Tapanainen, J., Orava, M. and Tuomivaara, L. (2000) One versus Two Embryo Transfer after In Vitro-Fertilization and ICSI: A Randomized Study. Human Reproduction, 6, 1900-1903. https://doi.org/10.1093/humrep/16.9.1900

[16] Ezugwu, E.C. and Van der Burg, S. (2015) Debating Elective Single Embryo Transfer after In Vitro Fertilization: A Plea for a Context Sensitive Approach. Annals of Medical and Health Sciences Research, 5, 1-7. https://doi.org/10.4103/2141-9248.149761

[17] Melgar, C.A., Rosenfeld, D.L., Rawlinson, K.E. and Greenberg, M.E. (1991) Perinatal Outcome after Multifetal Reduction to Twins Compared with Non-Reduced Multiple Gestations. Obstetrics and Gynecology, 78, 763-767.

[18] Zemet, R., Haas, J., Bart, Y., Barzilay, E., Zloto, K., Argaman, N., et al. (2019) Pregnancy Outcome after Multifetal Pregnancy Reduction of Triplets to Twins versus Reduction to Singleton. Reproductive BioMedicine Online. https://doi.org/10.1016/j.rbmo.2019.12.014 